\title{
Fostering Knowledge Sharing in NGOs
}

\author{
Adrian Holzer \\ EPFL \\ 1015 Lausanne, Switzerland \\ adrian.holzer@epfl.ch
}

\author{
Bruno Kocher \\ University of Lausanne \\ 1015 Lausanne, Switzerland \\ bruno.kocher@unil.ch
}

\author{
Samuel Bendahan \\ University of Lausanne \\ 1015 Lausanne, Switzerland
}

samuel.bendahan@unil.ch

\author{
Jorge Mazuze \\ Médecins Sans Frontières \\ 1201 Geneva, Switzerland \\ jorge.mazuze@geneva.msf.org
}

\author{
Denis Gillet \\ EPFL \\ 1015 Lausanne, Switzerland \\ denis.gillet@epfl.ch
}

\begin{abstract}
Non-Governmental Organizations in the humanitarian field are particularly knowledge intensive structures. However, they often fail to manage this knowledge efficiently and thus waste resources repeating avoidable mistakes. Providing adequate incentives for knowledge sharing is a central issue in any knowledge management system and is still largely unresolved. In this position paper, we advocate for advances on the topic and lay out a research agenda to address the issue.
\end{abstract}

\section{CCS Concepts}

- Information systems $\rightarrow$ Information systems applications management systems $\rightarrow$ Collaborative and social computing systems and tools

\section{Keywords}

Knowledge Management Systems; Motivation; Tangible objects

\section{INTRODUCTION}

With international relations becoming more complex, the role of the representatives of civil society is bound to become more important. The increase in the number of non-governmental organizations (NGOs) is witness to this evolution. Currently the United Nations registered over 22'000 NGOs (see http://esango.un.org). In order to perform their mission effectively, NGOs need timely and reliable access to critical information in the field. They need to be able to build and share knowledge efficiently between different, often geographically dispersed, teams. Research suggests that in order to support knowledge management, systems should include information sharing facilities within and between organizations, social features and involve multiple stakeholders in its design in order to avoid pitfalls [17]. Nevertheless, these features do not guarantee user engagement and researchers indicate that adequate incentives for participation are needed, especially in a framework where knowledge sharing is not the primary mission.

Permission to make digital or hard copies of part or all of this work for personal or classroom use is granted without fee provided that copies are not made or distributed for profit or commercial advantage and that copies bear this notice and the full citation on the first page. Copyrights for thirdparty components of this work must be honored. For all other uses, contact the Owner/Author.

Copyright is held by the owner/author(s).

ICTD '16, June 03-06, 2016, Ann Arbor, MI, USA

ACM 978-1-4503-4306-0/16/06.

http://dx.doi.org/10.1145/2909609.2909614
Incentives could range from managerial incentives (e.g., allocate time to share information) to digital interventions (e.g., gamification). Unfortunately, what kind of incentives are effective is still an unresolved issue [23]. In this paper, we advocate for the investigation of this issue and propose research questions to guide future research.

\section{BACKGROUND}

Hereafter, we discuss existing work investigating knowledge management in general and in the context of development and point at shortcomings. Knowledge management can be defined as the "process which facilitates knowledge creation and sharing through corporate intranets and communities of practice" [37]. In their seminal work on knowledge management, Alavi and Leidner (2001) [1] set the foundations of the research on the topic by reviewing existing literature and putting forth a set of research questions about knowledge management which focused on providing support for the creation, storage, retrieval, transfer and application of knowledge. Fast forward to 2014 and hundreds of articles later, it seems that many issues are still unresolved. More specifically, Wang et al. [15], warn that "Developing and introducing a state-of-the-art Knowledge Management Systems (KMS) and encouraging employees to use it only to share knowledge will likely be a wasted financial investment because of the low level of knowledge sharing that occurs." Along the same line, Leonard [30] insists on putting systems in place to encourage knowledge sharing before knowledge loss and hoarding cripple organizations.

NGOs have been recognized as knowledge-intensive organizations $[32,25,11]$. Their knowledge can be described as heterogeneous, rarely formalized and unstable due to the considerable turnover rates among volunteer workers [32]. These organizations have a paradox of specialized yet participative knowledge production where many stakeholders must be involved [11]. As such, managing knowledge is particularly important in these organizations, but most of them struggle with it $[25,40]$. For instance, among the symptoms of inefficient knowledge management one finds highly qualified workers wasting time looking for needed information, availability of essential know-how only in the heads of a few employees, or access to information hindered by piles of irrelevant data. With inefficient knowledge management, there is an increase in cost of errors which could be avoided if previous experience was taken into account [11].

The level of knowledge management in organizations can be described in levels from more simple to more sophisticated [9, $17,23]$. On the simplest level, knowledge is seen as a commodity 
and the role of IT is seen as deterministic. On the next level, organizations realize that knowledge (implicit and explicit) is an asset that needs to be managed. The focus is on intraorganizational knowledge management. On the third level, knowledge sharing spills over to other organizations. Sharing knowledge outside of the organization is one of the key specificities of NGOs as opposed to for-profit organizations [40]. Contrary to traditional management approaches where such sharing can be considered a threat, it can also be viewed as an opportunity to find strength in differences between cultures (whether between organizations or from other parts within an organization) [29]. Hurley and Green [26] argue that funding agencies are particularly eager to encourage knowledge sharing between organizations. Sharing knowledge implies that organizational silos are overcome and that organizations transit from a culture of information hoarding to information sharing [8]. On the fourth level, organizations embrace social media and the role of IT shifts from being central to being supportive. Whereas, social media were first used as external communication channels mainly for marketing (e.g., through a company Facebook page), they are more and more used as internal communication channels. Social media can also help in creating social capital, such as helping people know about others in the organization or breaking silos [23] even though these aspects are still challenging [21]. Status displays (e.g., on Facebook) and skill display (e.g., on LinkedIn) are now intrinsically part of social media. This trend is thus paving the way towards further acceptance in organizations.

Finally, Cummings et al. [9] propose, in the context of knowledge management for development (KM4D), to go one step further to a fifth level (or fifth generation). They argue for a transdisciplinary approach crossing the academic barrier to include societal issues. A key concept of the fifth generation of knowledge management for development is the understanding that knowledge is a public good [38], i.e., a good that can be consumed by one individual without reducing the potential amount available for others. Cummings et al. [9] argue that this is the desired direction for KM4D. We concur and strive towards this goal with this research agenda. This approach implies addressing real world problems, involving multiple stakeholders and using an iterative process that follows an emergent design. An emergent design means that the problem is reconsidered based on new observations as the project is already deployed. Indeed, failure to include stakeholders in the design phase is seen as a major reason for failures in knowledge management [8].

\section{FOSTERING KNOWLEDGE SHARING}

Fostering adoption of any software is a challenge. In a KMS the challenge is increased by the fact that the value of the system is created by the content provided by knowledge contributors, creating a cold start issue, i.e., users will be attracted to a platform with lots of content and users. In such a context, it is critical to find the adequate motivations and incentives to encourage knowledge contributors. However, research suggests that finding such incentives is still a largely unresolved issue [23]. This leads to the overarching research question:

RQ1: What kind of incentives can increase knowledge sharing in NGOs?

In order to investigate this overarching research question we propose to further understand user motivation, investigate how motivation can be triggered in a digital system and how motivation can move back from the digital system into the real world.

\subsection{Triggering motivation in a digital system}

The theoretical perspective of motivation of human behavior is considered to still be under-utilized in Information Systems research in general [4]. Motivations can be intrinsic (for its own sake) or extrinsic (depending on rewards or punishments resulting from the behavior) [6]. Intrinsic motivation is generally considered a more potent lever than extrinsic motivation. Early research on user contribution to communities, such as peer-topeer file sharing suggests that both extrinsic factors, such as external rewards or expectation of help in return, as well as intrinsic motivations, such as an increase in positive reputation or a sense of efficacy or commitment to a group, could drive motivation in these contexts [28,33]. From a purely managerial perspective, Wang et al. [15] find that rewards can increase knowledge sharing, especially for individuals with the following three personality traits: conscientiousness, neuroticism, and openness to experience. More recently, Zhang [4] suggests that information systems should have motivational affordances, i.e., properties of an object that determine whether and how it can support one's motivational needs, and proposes the following 10 design principles: (1) Support autonomy, (2) Promote creation and representation of self-identity, (3) Design for optimal challenge, (4) Provide timely and positive feedback, (5) Facilitate human-human interaction, (6) Represent human social bond, (7) Facilitate one's desire to influence others, (8) Facilitate one's desire to be influenced by others, (9) Induce intended emotions via initial exposure to ICT, (10) Induce intended emotions via interaction with ICT.

Several of these principles are strongly related to the trendy research field of gamification, where game-like features serve as motivational affordances in non-game systems $[10,18]$. With gamification, both intrinsic and extrinsic motivations can be afforded [36]. Typical motivational affordances in such systems include points, leader boards, achievements/badges, levels, story/themes, clear goals, feedback, rewards, progress, and challenges [22]. Despite the large interest in gamification, there are only few studies looking at gamification to foster participation in the organizational context. For instance in the recent systematic literature review on empirical evaluations of gamification [22] the authors only report on 4 studies in the organizational context out of 24 and all by the same group at IBM Research $[31,16]$. In their most recent work, Millen and DiMicco investigated how removing the gamification features of an enterprise social network system affects behavior [31]. Their results show that the removal reduced overall participation via contributions on the system. In their analysis, incentive system worked very well during the first three weeks and then declined [16]. Note that the effects of adding gamification on user engagement are not yet clear cut [18] and generally gamification studies do not have strong experimental validity [22]. For instance, Hamari et al. [22] indicate that studies so far are small, lack proper validated psychometric measurements, lack controls between implemented motivational affordances, and no single study in their review used multilevel measurement models including motivational affordances, psychological outcomes, and behavioral outcomes.

To better understand the impact of gamification on behaviors, we rely on the literature on intrinsic motivation described in the psychological literature, which is particularly relevant in this context, and find appeal to status as a key characteristic. Status has been studied in a lot of different contexts and has been described as a key motivator in human behavior (for a review, see [2]). Recent research in social psychology distinguished status from similar concepts (e.g. status vs. power $[34,5])$ and assessed its principal antecedents and its main consequences (e.g. see $[3,39])$. Research in organizational behavior has also studied 
status in relationship to a variety of variables such as favor exchange and productivity [19], procedural justice [7, 24] and its dynamics [14, 35]. Most relevant in the context of NGO delegates is the concept of status which is defined as the amount of respect, influence, and prominence an individual enjoys in the eyes of others [2,3]. Due to the specificities of knowledge management in NGOs, there is currently a lack of understanding of the kind of sociometric status lever that can motivate users in a heterogeneous, non-formalized and non-face-to-face environment. This gap leads to the following questions:

RQ2: What are the sociometric status levers that motivate knowledge sharing among NGO members?

RQ3: How can digital motivational affordances reflect sociometric status in the context of KMS for NGOs?

RQ4: How can digital motivational affordances trigger knowledge sharing in the context of KMS for NGOs?

In order to address these questions one can aim to designing useful and attractive motivational affordances targeting motivations elicited by RQ2 and investigate the affordance of innovative embedded artifacts providing incentive for knowledge sharing using a participatory design methodology. Among the motivational affordances that can be used to address this issue we can imagine achievements (received after a certain amount of actions performed), badges (based on social ratings by peers), and points (overall scores based on activity), and possibly leaderboards. An important focus should hence be put on designing motivational affordances which simultaneously take into account the willingness of users to disclose traces of their activities and to access to ones of others through proper control mechanisms.

\subsection{Interplay of Digital and F2F Interaction}

In order to make the transition between the digital and real world more seamless, researchers have suggested to investigate tangible computing [27]. The idea behind tangible computing is to embody digital artifacts in common objects to lower the access barrier to the world of bits. Interactive tabletops or ambient rooms are poster children of such endeavors. Gamification, by itself can also be seen as embodied attributes of everyday experience in the digital realm [13] but can also be further extended and embodied in tangible objects. Givold and Aarseth [20] relate experiences with tangible interfaces and gamification for asthma patients. They describe the AsthmaBuddy, a teddy bear with an integrated Raspberry Pi that teaches children with asthma when to take their medicine. The bear works together with a mobile app that keeps track of points collected by the child and the bear can teach the child about asthma care and it can tell the child about its score through a microphone. In management information systems, the topic of tangible objects is still in its infancy. Yoo [12] set up a research agenda to integrate tangible objects in information systems research and expanded the scope of research beyond computer software to include all science of the artificial in everyday life experience. This research gap leads to the following open research question:

RQ5: How can tangible components of a system improve the transition from digital to face-to-face interaction?

This question is particularly important in the NGO contexts in which knowledge management is not the primary mission (e.g., humanitarian NGOs are more about handling emergency situations and saving lives), "incentives" to share knowledge should be embedded in the objects the volunteers are using daily in their humanitarian practice (e.g., wearable devices, smart medical devices, or physical badges)

\section{CONCLUSION}

As knowledge intensive organizations, NGOs need to manage knowledge efficiently. Unfortunately, they often struggle to do so in practice and encourage their members to share their knowledge in a systematic way. Furthermore, current research literature is still lacking a full understanding on how to encourage users to share knowledge. In this paper we attempted to provide a roadmap of the open questions that still need to be addressed. To effectively answer these questions, researchers should adopt a transdisciplinary approach using complementary perspectives and research methods blending fields such as human computer interaction, behavioral science, or psychology, with expertise from designers as well as from stakeholders from the field.

\section{ACKNOWLEDGEMENTS}

This study is partly funded by the joint Collaborative Research on Science and Society (CROSS) program of EPFL and the University of Lausanne (UNIL).

\section{REFERENCES}

[1] Alavi, M. and D. E. Leidner (2001), Review: Knowledge management and knowledge management systems: Conceptual foundations and research issues, MISQ, 107-136.

[2] Anderson, C. J., A. Hildreth, and L. Howland (2015), Is the desire for status a fundamental human motive? A review of the empirical literature, Psychological Bulletin, 141(3), 574601.

[3] Anderson, C., O. John, D. Keltner, and A. M. Kring (2001), Who attains social status? Effects of personality and physical attractiveness in social groups, Journal of Personality and Social Psychology, 81 (1), 116-32.

[4] Zhang, P. (2008), Technical opinion Motivational affordances: reasons for ICT design and use, CACM 51(11), 145-147.

[5] Blader, S. L., and Y. Chen (2012), Differentiating the effects of status and power: A justice perspective, Journal of Personality and Social Psychology, 102 (5), 994-1014.

[6] Brown, L. V. (2007), Psychology of motivation. Nova Publishers.6. Knowledge management in non-governmental organizations, In Enterprise Inf. Systems VII. 121-130.

[7] Chen, Y., J. Brockner, and J. Greenberg (2003), When is it "a pleasure to do business with you?" The effects of relative status, outcome favorability, and procedural fairness, Organizational Behavior and Human Decision Processes, 92, $1-21$.

[8] Coakes, E., A. D. Amar, and M. L. Granados (2013), Success or failure in knowledge management systems: A universal issue, In Grand Successes and Failures in IT. Public and Private Sectors. Springer, 39-56.

[9] Cummings, S., B. Regeer, W. Ho, and M. Zweekhorst (2013), Proposing a fifth generation of knowledge management for development: investigating convergence between knowledge management for development and transdisciplinary research, Knowledge Management for Development Journal, 9(2), 10-36.

[10] Deterding, S., D. Dixon, R. Khaled, and L. Nacke (2011), From game design elements to gamefulness: defining gamification, In MindTrek'11. ACM, 9-15.

[11] de Vasconcelos, J. B., P. C. Seixas, P. G. Lemos, and C. Kimble (2006), Knowledge management in non- 
governmental organizations, In Enterprise Inf. Sys. VII. Springer, 121-130.

[12] Yoo, Y. (2010), Computing in everyday life: A call for research on experiential computing. MISQ, 34(2), 213-231.

[13] Eriksson, B., Musialik, M., \& Wagner, J. (2012). Gamification-Engaging the Future.

[14] Washington, M., and E. J. Zajac (2005), Status evolution and competition: Theory and evidence, Academy of Management Journal, 48(2), 282-296.

[15] Wang, S., R. R. Noe, and Z.- M. Wang (2014), Motivating knowledge sharing in knowledge management systems: A quasi-field experiment, J. of Management, 40(4), 978-1009.

[16] Farzan, R., J. M. DiMicco, D. R Millen, C. Dugan, W. Geyer, and E. A. Brownholtz (2008b). Results from deploying a participation incentive mechanism within the enterprise. In CHI'08. ACM, 563-572.

[17] Ferguson, J.E., K. Mchombu, and S. Cummings (2008), Management of knowledge for development: meta-review and scoping study. Amsterdam: IKM Working Paper.

[18] Fitz-Walter, Z., P. Wyeth, D. Tjondronegoro, and D. Johnson (2014), Exploring the effect of achievements on students attending university orientation. In ACM PLAY'14.

[19] Flynn, F. J. (2003), How much should I give and how often? The effects of generosity and frequency of favor exchange on social status and productivity, The Academy of Management Journal, 46 (5), 539-553.

[20] Gisvold, A., \& Aarseth, E. (2014). Using Gamification and Tangible User Interfaces to Treat Asthmatic Children. NTNU Trondheim, Norwegian University of Science and Technology.

[21] Voida, A. E. Harmon, and B. Al-Ani (2012), Bridging between organizations and the public: volunteer coordinators' uneasy relationship with social computing, In CHI'12. ACM.

[22] Hamari, J., J. Koivisto, and H. Sarsa (2014), Does gamification work?-a literature review of empirical studies on gamification, In HICSS'14, 2014. IEEE, 3025-3034.

[23] Van Osch, W., C. W. Steinfield, B. Balogh (2015), Enterprise Social Media: Challenges and Opportunities for Organizational Communication and Collaboration. In HICSS'15, 763-772.

[24] Tyler, T. R., and S. L. Blader (2002), Autonomous vs. comparative status: Must we be better than others to feel good about ourselves? Org. Behavior \& Hu. Dec. Proc., 89, 813-838.

[25] Hume C. and M. Hume (2015), The critical role of internal marketing in knowledge management in not-for-profit organizations, J. of Nonprofit \& Pub. Sect. Mark., 27(1), 2347.

[26] Hurley, T. A., and C. W. Green (2005), Knowledge management and the nonprofit industry: A within and between approach, Journal of Knowledge Management Practice 6, (1).

[27] Ishii, H. and B. Ullmer (1997), Tangible bits: towards seamless interfaces between people, bits and atoms. In CHI'97. ACM, 1997.

[28] Kollock, P. (1999), The economies of online cooperation, Communities in cyberspace 220.

[29] Le Borgne E.,S. Cummings (2009), The tip of the iceberg: tentative first steps in cross-organizational comparison of knowledge management in development organizations. Knowledge Management for Development Jour.5(1 ), 39-60.

[30] Leonard, D., (2014), How to prevent experts from hoarding knowledge, Harvard Business Review, Dec. 18, 2014.
[31] Thom, J. D. Millen, and J. DiMicco (2012), Removing gamification from an enterprise SNS. In CSCW'12. ACM, 1067-1070.

[32] Lettieri, E., F. Borga, and A. Savoldelli (2004), Knowledge management in non-profit organizations, Journal of Knowledge Management, 8(6), 16-30.

[33] Lui, S. M., K. R. Lang, and S. H. Kwok (2002), Participation incentive mechanisms in peer-to-peer subscription systems, In System Sciences, 2002. In HICSS'02. IEEE, 3925-3931.

[34] Magee, J.C., and A. D. Galinsky (2008), The selfreinforcing nature of social hierarchy: Origins and consequences of power and status, IACM 21st Annual Conference Paper.

[35] Marr J.C., and S. Thau (2014), Falling from great (and not so great) heights: Status loss and performance in groups, Academy of Management Journal, 57, 223-248.

[36] Muntean, C. I (2011), Raising engagement in e-learning through gamification, In Proc. 6th International Conference on Virtual Learning ICVL. 323-329.

[37] Pan, S. L. and H Scarbrough (1999), Knowledge management in practice: An exploratory case study, Technology Analysis \& Strategic Mngmnt, 11 (3), 359-374.

[38] Stiglitz, J. E. and B. C. Greenwald (2014), Creating a learning society: a new approach to growth, development, and social progress. Columbia University Press

[39] Pettit, N. C., N. Sivanathan, E. Gladstone, and J. C. Marr (2013), Rising stars and sinking ships: Consequences of status momentum, Psychological Science, 24 (8), 1579-1584.

[40] Renshaw, S., and G. Krishnaswamy (2009), Critiquing the knowledge management strategies of non-profit organizations in Australia. In WASET'09, 37 (2009), 456464. 